\title{
Osteopaths' professional views, identities and conceptions e A qualitative grounded theory study
}

\author{
Oliver P. Thomson, Nicola J. Petty, Ann P. Moore
}

\section{KEYWORDS}

Osteopathy; Osteopathic medicine; Knowledge; Decision-making; Clinical reasoning; Professionalisation; Professional identity; Grounded theory

\section{Abstract}

Background: The professional status of osteopathy calls for the critical evaluation of the beliefs, knowledge and conceptions which underlie practitioners' clinical practice.

Objectives: To explore experienced osteopaths' professional identities, views and overall conceptions of osteopathy in the UK.

Methods: This qualitative study employed constructivist grounded theory set in the interpretive research paradigm. The constant comparative method of analysis was used to analyse and code interview data. A total of seventeen semi-structured in- terviews were conducted with twelve UK registered osteopaths. Data collection methods involved semi-structured interviews with participants and observation and video-recording of clinical appointments, which were followed by video- prompted reflective interviews.

Results: There was diversity in how osteopaths viewed different aspects of their professional practice. Views were constructed into the major categories of: profes- sional identity, traditional osteopathic theories and principles, health and disease and practice skills. Together these views formed three qualitatively different overall conceptions of osteopathy, termed: practitioner-centred osteopathy, collaborative osteopathy, and osteopathy as empowerment.

Conclusions: Osteopaths in this study held differing views, identities and concep- tions in relation to their practise of osteopathy. This diversity in professional identi- ties and conceptions may help to explain the variation of individual osteopaths' clinical decision-making and clinical approaches, thereby contributing to an episte- mology of osteopathy. These findings may be helpful to educators when planning curricula and clinically tutoring osteopathy students. Further research is required to explore how these views and conceptions develop and evolve during undergradu- ate education and on-going professional development

\section{Implications for practice}

- As professionals, osteopaths are required to critically examine the views, beliefs and conceptions that underlie their clinical work.

- There is diversity in the range of views that experienced osteopaths hold in relation to core aspects of their practice.

- How an individual practitioner conceives the nature of osteopathy and identifies with their profession may influence their clinical decisionmaking and the clinical approaches they take with their patients.

- As knowledge and practice are constantly changing, practitioners should critically reflect on their own personal conceptions of osteopathy and how these relate to their clinical decision-making and practice. 



\section{Introduction}

In many countries, osteopathy has undergone a process of 'professionalisation', which Cant and Shamar define as a "type of occupational change and formation that involves unification, standardisation, and the acquisition of external legitimacy"., ${ }^{1, p} 197$ There is evidence of the professionalisation of osteopathy in several corners of the world and different countries are at varying stages of the process. For example, in the USA the formal process of professionalisation of osteopathy first began in the early 1960s, and has resulted in the establishment of an osteopathic 'medical' profession which enjoys the full range of clinical practices and procedures employed by the orthodox medical profession, in addition to osteopathic manipulative therapy. ${ }^{2}$ In comparison, osteopathy in the UK and the antipodes is considered to be an emerging manual therapy profession ${ }^{3 \mathrm{e} 5}$ where professionalisation has taken place since the early 1990s. Examples of strategies taken to facilitate the process of professionalisation of osteopathy in the UK and antipodes include ${ }^{3 e 5}: 1$ ) the formation of a single statutory register of osteopaths; 2) a regulatory body which sets standards of practice and training; 3) structured and externally inspected educational programmes; 4) legally protected professional title of 'Osteopath'; and 5) measures in place to discredit those practitioners who do not practice to agreed standards. All of these strategies have provided osteopathy with unity, exclusivity and social closure which are considered to be characteristics of a profession. ${ }^{1}$

The professional status of osteopathy carries with it the requirement to be critically reflective, and to constantly self-evaluate and self-question in order to develop the knowledge base which underpins clinical practice and also to understand how osteopaths know, what they know (an epis- temology of practice). ${ }^{6}$ Although a challenging process, identifying an epistemology of osteopathy through critical enquiry and research is crucial to the continued development of the osteopathic profession. A number of other healthcare pro- fessions have discussed the importance of devel-

oping an epistemology of practice, including the physiotherapy ${ }^{7 e 10}$ and nursing professions. ${ }^{11,12} \quad$ Although osteopaths' professional knowledge, values and beliefs has been discussed theoreti- cally, ${ }^{13,14}$ and investigated in relation to specific aspects of clinical practice (e.g. prescription rights ${ }^{15}$ and chronic musculoskeletal pain ${ }^{16}$ ), there is little research-based knowledge of how practi-

tioners conceive osteopathic practice and how this influences their clinical work. Developing an epis- temology of osteopathy through research would allow for the identification of the tacit or non- propositional knowledge used by practitioners, as they work through the complex problems of daily practice. Research of this kind would help to un- derstand what motivates individual practitioners' actions and decisionmaking when working clini- cally with patients. Furthermore, research which develops knowledge of what steers osteopaths' clinical actions and behaviour would facilitate 
clinical educators when working alongside students and also provide an understanding of the range of professional identities which could be embedded within osteopathic curricular. ${ }^{17}$ Our recent research suggests that how osteopaths conceive the nature of their practice (practice ontology) influences their clinical work and their views on knowledge (epistemology of practice knowledge), decision-making and technical skills and may help to explain the variation in clinical approaches (e.g. during treatment and management) that each osteopath takes with their patients. ${ }^{18,19}$ How an individual practitioner's personal conception of practice develops and changes during the course of their professional life is thought to be related to how they identify with their profession, their professional values and is ultimately tied to their interactions with patients which take place during the clinical milieu. ${ }^{19 \mathrm{e} 21}$ The physiotherapy literature suggests that practitioners' professional values and identities develop during their interaction and socialisation with peers during their undergraduate education and continues throughout their professional careers when interacting with professional colleagues. ${ }^{22}$ The nature of osteopaths' professional values, conceptions and identities is yet to be investigated, and how these relate to their views on the treatment and management of patients is currently unknown.

This paper explores experienced osteopaths' professional identities, views and overall conceptions of osteopathy, and the findings from this study form part of a broader theory of osteopaths' clinical decision-making and therapeutic approaches reported elsewhere. ${ }^{18,19,23}$

\section{Methods}

\section{Study design}

This qualitative study followed a constructivist grounded theory approach, with the primary researcher (OT) iterating between data collection and data analysis. ${ }^{24}$ In accordance with interpretive research, ${ }^{25}$ throughout this study, OT assumed "multiple realities; indeterminacy; facts and values as linked; truth as provisional; and social life as processual". ${ }^{24, p .126}$ In practice this meant that during data collection the researcher explored the social worlds of participants and coconstructed knowledge and meaning through a socially interactive process. ${ }^{25,26}$ The constant comparative method of analysis was used to code and analyse data. ${ }^{24}$ This involved OT reading and re-reading the transcripts, whilst looking for patterns in the data (such as differences and commonalities across the data and between and within participants) and allocating segments of data a code based on an interpretation. Memos were written throughout the course of the study and facilitated OT's reflexivity by explicating a priori biases, assumptions and presuppositions which could be checked out and tested with the data, thereby contributing to the credibility of the research. ${ }^{27}$ Memo-writing also facilitated data analysis and theory development by critically questioning data and forming hypotheses which were generated by the constant comparative method of analysis. ${ }^{24}$

Initially, experienced osteopaths with a minimum of five years in clinical practice and who were involved in clinical education, were sampled purposefully as it was thought that these individuals would be 'good informants' and able to effectively communicate and verbalise their professional views. ${ }^{28}$ In the latter stages of the study, theoretical sampling, informed by data analysis, led to specific participants and individuals not involved in clinical education to be sampled. ${ }^{24}$ For example, participants 1 and 10 were theoretically sampled and re-interviewed as they each appeared to conceive osteopathy in quite different and distinct ways. This theory-led approach to sampling aimed to generate data that would help develop categories and their properties and move the study's findings towards theoretical sufficiency. ${ }^{24}$

Data collection methods involved semistructured interviews and non-participant observation of practitioners during a patient appointment, which was video-recorded and followed by a video-prompted reflective interview. ${ }^{29} \mathrm{~A}$ total of seventeen semi-structured interviews were conducted, three of which occurred immediately after a patient appointment and were prompted by the video-recording of the session. ${ }^{29}$ The decision to incorporate video-recording and video-prompted reflective interviews as a method of data collection was theory-led and constituted part of theoretical sampling. ${ }^{24}$ It provided further specific data about how participants acted-out their views, conceptions and identities, in the context of their clinical work with patients. All interviews were audio-recorded and transcribed verbatim. The methods of data collection and analysis used in this study have been presented in detail elsewhere. ${ }^{18,23,30}$ A number of strategies were used to enhance the trustworthiness of this study, ${ }^{31}$ and are summarised in Table 1. 
Table 1 Strategies used to enhance and evaluate the trustworthiness of this grounded theory study. ${ }^{30}$

$\begin{array}{ll}\text { Credibility } & \text { Description } \\ & \text { Confidence that the research has } \\ & \text { obtained an accurate } \\ \text { interpretation of the meaning of } & \text { the data which reflects the } \\ & \text { experience of participants. }\end{array}$

Transferability

Dependability and confirmability
Transferability is the extent to which the ideas generated may be applied to other populations or situations, and may be considered the theoretical generalisability of the findings

The degree to which the researcher can demonstrate that the findings relate to the data. Whether the findings of the study offer a dependable and realistic interpretation of the view held by the participants.
Strategies

- Prolonged immersion in the data (3 years).

- 'Insider' position as an osteopath provided opportunities to informally verify, test and check the theory as it was constructed during the analysis.

- Member checking e Participants were asked to read through the interview transcript to confirm or refute that it represented an accurate account of what was said, and were encouraged to add any further comments that they felt necessary.

- Peer debriefing in the form of feedback from the peer review process following the submission of sections of study to research journals and conferences.

- A well-developed researcherparticipant relationship so that participants had trust in disclosing personal details of their clinical practice.

- A reflexive diary was kept to disclose assumptions, biases and beliefs, and how they have shaped the research findings.

- During interviews, the goal was to obtain "thick descriptions", i.e. those which were "deep, dense, detailed accounts." 32,p.83

- Ideas and theories were discussed with osteopathic colleagues not involved in the study.

- An audit trail in the form of memos, reflexive diary and interview transcripts so that the reader can follow the research process.

- The word allowance of this paper limits this, a fuller account can be found elsewhere. ${ }^{18,19,23,30}$

\section{Participants}

A total of twelve UK registered osteopaths took part in this study. Participants' were recruited from adverts placed in the national osteopathic press and in osteopathic educational institutions (OEI). Participants' biographical information is provided in Table 2. Approval was granted by the Faculty of Health and Social Science Research Ethics and Governance Committee at the University of Brighton and the Ethics Committee of the British College of Osteopathic Medicine.

\section{Findings}

Participants expressed a range of views and perceptions in relation to many different aspects of osteopathy. These professional views are divided into five major categories:

- professional identity

- traditional osteopathic theories and principles

- health and disease

- practice skills

- conception of osteopathy. 


\begin{tabular}{|c|c|}
\hline $\begin{array}{l}\text { Table } 2 \text { Biographical } \\
\text { participants. }\end{array}$ & information of study \\
\hline Mean age (years) & 43.5 (range 30e56) \\
\hline $\begin{array}{l}\text { Mean years in clinical } \\
\text { practice }\end{array}$ & 15 (range 6e25) \\
\hline Gender & $\begin{array}{l}10 \text { males } \\
2 \text { females }\end{array}$ \\
\hline Work setting & $\begin{array}{l}\text { All worked in private } \\
\text { clinical practice } \\
10 \text { held additional } \\
\text { roles as clinical } \\
\text { tutors or lecturers } \\
\text { at an osteopathic } \\
\text { educational } \\
\text { institution }\end{array}$ \\
\hline Education & $\begin{array}{l}\text { All had undergraduate } \\
\text { qualification in } \\
\text { osteopathy (BSc, DO) } \\
4 \text { held additional } \\
\text { postgraduate } \\
\text { degrees (MSc) }\end{array}$ \\
\hline
\end{tabular}

The categories are discussed in turn and supported with participants' quotations from interview data which serve as evidence for the theoretical claims made in this paper. Table 3 and Fig. 1 summarise the five major categories.

\section{Professional identity}

There was variation in how participants viewed themselves as osteopaths in the context of their professional work, and how they viewed osteopathy in relation to other healthcare professions, which together constituted their professional identity. Five participants $(P 1,4,5,11,12)$ considered that as osteopaths, they were particularly different from other healthcare professionals, and that osteopathy was defined by distinct osteopathic values, skills and knowledge. These participants looked to defend osteopathy, and frequently drew comparisons with other similar health professions to highlight professional differences:

Chiropractors and physios don't have that truly holistic approach that we [osteopaths] have. (P5)

Osteopaths look at the whole person more than the average doctor. [and] that's why I wanted to become an osteopath and not a GP. (P4)

These participants tended to value approaches to osteopathy based on long-established traditions and some felt strongly that the specific skills and

Table 3 Summary of participants' professional views.

\section{Professional identity}

Strong and well defined: Osteopathy's whole system [of treatment] is based upon what we see structurally and what we are feeling passively. (P12)

Undefined; ambivalent: I don't think that osteopaths do anything which is particularly unique, to be honest. (P6)

Traditional osteopathic principles and theories

Defensive stance; principles and theories inform practice: The philosophical thoughts of Andrew Taylor Still and those people are what l've always gone back to. I've always read the old osteopathic stuff (P1)

Critical stance; towards theories and principles: I don't believe that we should be obsessed with the principles of osteopathy, or things like movement dysfunction, or positional lesions, I've thrown them out the window. (P3)

They [the osteopathic principles] were just musings of an old man. [and] they're just observations of physiology from the late eighteenth century rather than directives. (P6)

Health and disease

Towards a biomedical view: If you don't have the basics like anatomy and physiology you are never going to get the right decision. If you know your basics you can get to the right decision very quickly. (P12)

Towards a biopsychosocial view: I like to see the other factors that would be influencing the way that they [the patient] experience their problem.it gives you a much rounder picture of the person you're treating. (P6)

Practice skills

Emphasis on hands-on skills: Usually my treatments will start with quite a lot of palpation and soft tissue e I use soft tissue techniques with $95 \%$ of my patients.to loosen the tissues and developing into joint work, HVTs, mobilising [the joints] once you've softened the tissues. (P5)

Emphasis on communication skills: I like to spend time just talking to the person about what's going on and how it's impacting them.(P7)

Emphasis on educational skills: I really believe in this notion of patient autonomy and I think patients are responsible for themselves.and. if they can work out why it's there and what they can do to stop it or control it, it gives them back their control. (P6) 
theories which they possessed were central to their practise of osteopathy:

Osteopathically it's our philosophical idea that is central to osteopathy. (P1)

Palpation is essential to the osteopath. If you don't know what's underneath your fingers then don't touch the body. It's as simple as that. (P12)

In contrast, several other participants $(P 2,3,6,9,10)$ did not consider osteopathy as being a distinct discipline different from other healthcare professions and had less-defined professional identities. These participants tended to highlight the similarities of osteopathy compared to other professions:

If you go with shoulder pain to a physio, a chiropractor, and osteopath, it's the same thing.we're all dealing with the same things. So over the years it's getting to the point where all professions look at things similarly. (P2)

Osteopaths don't do anything new. chiropractors have been doing it for a while; physios, massage therapists [and] rolfers do the same. (P3)

Other professions do exactly the same as us.certainly the ones that l've worked with. (P10)

Participants that were ambivalent and who held less-defined professional identities considered that their clinical practice entailed more than just the application of osteopathic skills, theories and knowledge, and they appeared self-assured in their own personal style and approach to practice:

Rather than just being an osteopath who does osteopathy, I see myself as a person who will actually help facilitate patients' recovery. (P7)

I'm not concerned about being called an 'osteopath', it's just a title that allows me to do what I do with my patients.[so] the word 'osteopath' isn't important to me, the word 'clinician' is better. (P3)

Overall, there were some participants that had well-defined professional identities and defended the distinctiveness of osteopathy by emphasising what they considered to be the strengths compared to other healthcare professions. They considered that specific osteopathic skills, knowledge and theories separated them from other professions and shaped their professional identity. There were other participants who were ambivalent and did not emphasise interprofessional differences and had less-defined professional identities.

Traditional osteopathic theories and principles

Participants expressed a wide range of views on traditional osteopathic theories and principles (for example $\left.e^{33,34}\right)$. Several participants $(P 1,2,8,11,12)$ valued particular time-honoured osteopathic theories and principles and considered that these formed specialised osteopathic knowledge which guided their clinical work:

The osteopathic concept that the body is its own medicine chest is one that I very much believe. [and] that's where I think my approach becomes osteopathic. (P12)

There's only one osteopathic principle, which is what A.T Still discovered, that you could treat any symptom by working on the body. (P2)

The principles of osteopathy are instinctive to me and make me do what I do. (P1)

These participants perceived that osteopathy incorporated unique concepts of health, illness and diagnosis and defended the importance of these for clinical practice. They tended to consider that long-established osteopathic principles should remain unchanged over time, and that the original ideas and theories derived from important individuals within the osteopathic profession were valuable to inform their decisionmaking and clinical work:

You have to think osteopathically, 'What are the fluid mechanics like? What's happening? Are the tissues being bathed?' (P8)

You need to keep pure to the osteopathic philosophical idea.[and] I still operate from an old school point of view, where I use palpation to tell me what to do.[because] the principle of removing obstacles from the patient's body, from an osteopathic point of view, is very important to me. (P1)

However, views varied as suggested by the following comments from participants; some participants appeared ambivalent $(\mathrm{P} 4,5,9)$ as illustrated by the first comment; while other participants $(\mathrm{P} 3,6,7,10)$ were especially critical of 
traditional osteopathic theories and principles. Some of these participants believed that adhering to such time-honoured customs was detrimental to the osteopathic profession, as illustrated by the second and third comments:

I'm not so convinced on the A.T. Still stuff.I'm not sure that I'm following the principles. (P5)

Certain osteopathic institutions teach treatment algorithms that come from the sacred books of osteopathy.they're traditionalists that have an old-fashioned, paternalistic approach to patients.[which] I don't think is doing the profession much good at all. (P6)

A.T. Still had a good idea at the time, but for us to still remain by his book, like he's some form of deity, is absurd [so] there's a danger that some osteopaths will adhere to dogma (P3)

Overall, the variation in views suggests that there were participants who embraced traditional osteopathic theories and concepts, and applied these to their practice. Other participants appeared more critical of specific osteopathic principles and theories suggesting that they played a less important role in their clinical work. These participants appeared to be more comfortable developing their own clinical approaches and identities.

\section{Health and disease}

Views about health and disease differed amongst study participants. Almost half the participants $(P 1,2,5,8,11,12)$ expressed views that emphasised the physical, biological and physiological aspects of the patient's problem. These participants appeared to place less emphasis on the emotional and psychological experiences of the patient, and when talking about their views and practise of osteopathy they focused strongly on the patient's body, physical structure and biomechanics. This suggests that they viewed patients' problem through a predominantly biomedical lens:

If you know that the problem in the knee is caused by excessive rotation of the pelvis, then the [knee] ligament will be overloaded. So my work is to treat the compensations of the patient's body. (P1)

These participants tended to place high importance on their technical expertise and hands-on skills to assess and treat the patient, and in particular the identification of dysfunctional regions in the patient's body and tissues. Participants that emphasised biomedical and physical aspects of pain and disability $(P 1,2,5,8,12)$ tended to view patients' problem as separate from their social and emotional circumstances. These participants appeared to separate out patients' physical and mechanical problem from their lived experience and social circumstances:

I try and find the tissues causing symptoms, first and foremost; then I can satisfy myself that this is a simple facet lock [or] strain. (P2)

If I can find the exact action that produces pain then I can have an idea of what tissue is involved and start to think about treatment. (P5)

$A$ view of health and disease which emphasised the biomedical aspects of the patients problem, resulted in several participants $(P 1,2,5,8,12)$ emphasising their technical expertise and directed their skills in clinical examination towards discovering and separating out an 'objective dysfunctional entity':

If the patient has pins-and-needles in their legs, I need to establish exactly where the pins-andneedles are. (P12)

My goal is to identify the local problems within the knee and clear the symptoms with treatment. (P5)

In contrast, other participants $(\mathrm{P} 3,4,6,7,9,10)$ considered patients' problem in the context of their lives and their illness experience, suggesting a broader psychosocial view of health and disease, as illustrated by the two comments:

My [clinical] examination is a patient-specific functional assessment [to get] an overall picture of their pain and coping, in order to get a picture of what we're dealing with and how the person is dealing with it. (P9)

I always consider the physiological and psychological aspects of the patient and how those areas relate. that's what I consider holistic. (P7)

Overall, participants viewed health disease in different ways. Some appeared to separate out patients' physical and mechanical problem from their lived experience and social circumstances and held views of health and disease which leant 
towards a biomedical view. Several other participants saw the patient's pain and dysfunction as part of 'them' and their everyday lives, activities and experiences and held views which emphasised the psychosocial aspects of health and disease.

\section{Practice skills}

There was diversity in the type of skills that participants emphasised in their practice. Although, all participants employed hands-on skills in their clinical work; there was wide variation in the importance that manual techniques played in examination and treatment. Several participants $(P 1,2,5,8,12)$ emphasised the importance of hands-on skills and technical expertise often with the aim to try and discover and resolve the patient's physical impairment:

In my book the only reason why the patient has come to your practice is because they have lost the ability to move in a certain direction. (P1)

..the sense of touch and the sense of restriction, palpation helps you to identify tissue lesions or restrictions.it's about feeling and identifying areas of cold, stiff, tense muscles. (P5)

It's about my fingers giving me the information that I need, telling me about those tissues, the quality of them, what are they doing? Are they doing what they're supposed to be doing? What do they feel like? (P8)

I've got to feel [palpate] the rotation of each segment of his spine, of each segment in the flesh. (P 12)

In contrast other participants $(P 3,4,6,7,9,10)$ placed less significance on hands-on skills and manual therapy techniques directed to the patients' body. Three of these participants $(P 3,4,7)$ emphasised their communication skills and inter/ intrapersonal skills in addition to hands-on skills alone:

The physical examination is something that l'd be expected to do. but the value of the actual information is not critically important for me; I know how inaccurate the physical examination can be. (P10)

I can perform the hands-on stuff in the background which leaves me the capacity to talk to the patient.because I concentrate more on developing a relationship with the person. (P7)
While other participants that did not emphasise hands-on skills in their practice $(P 6,9,10)$ tended to accentuate education and self-management strategies in addition to manual therapy treatment. These participants emphasised working with patients to help them develop the skills to selfmanage their health problem:

Lots of what we see is brought upon by patients' bad habits or lack of knowledge [and] so with education it's all potentially preventable or selfmanageable. (P6)

Three participants $(P 3,6,10)$ that emphasised educational and communication skills in their practice appeared very critical of some of the hands-on aspects of osteopathy, for example:

To say that there's a movable skull that we can palpate, is ridiculous.[and] I'm happy to appraise the evidence and question it. (P3)

The osteopathic concept that your hands are the most important tools and you should rely on your hands because they never lie is fallacious. (P6)

Most of the hands-on stuff is nonsense. It just helps to loosen the patient off and make them feel $a$ bit better and more relaxed. (P10)

Overall, there was variation in the type of skills that participants emphasised in their practice. Some participants focused their clinical work on their hands-on skills and technical expertise, while others focused on the patient as a person and emphasised their communication, interpersonal and educational skills during their clinical practice. Participants' views on their professional identity, traditional osteopathic theories and principles, health and disease and practice skills are summarised in Table 3.

\section{Conception of osteopathy}

Participants' views on their professional identity, traditional osteopathic theories and principles, health and disease and practice skills formed an overall conception of the nature of osteopathy, resulting in three qualitatively different 'conceptions of osteopathy', which were termed: practitioner-centred, collaborative, and empowerment. This is not to suggest that all participants fitted distinctly in each conceptual category, rather it offers a crude differentiation of the diverse views that participants' held, allowing for theoretical comparison. These are illustrated in Fig. 1 and 


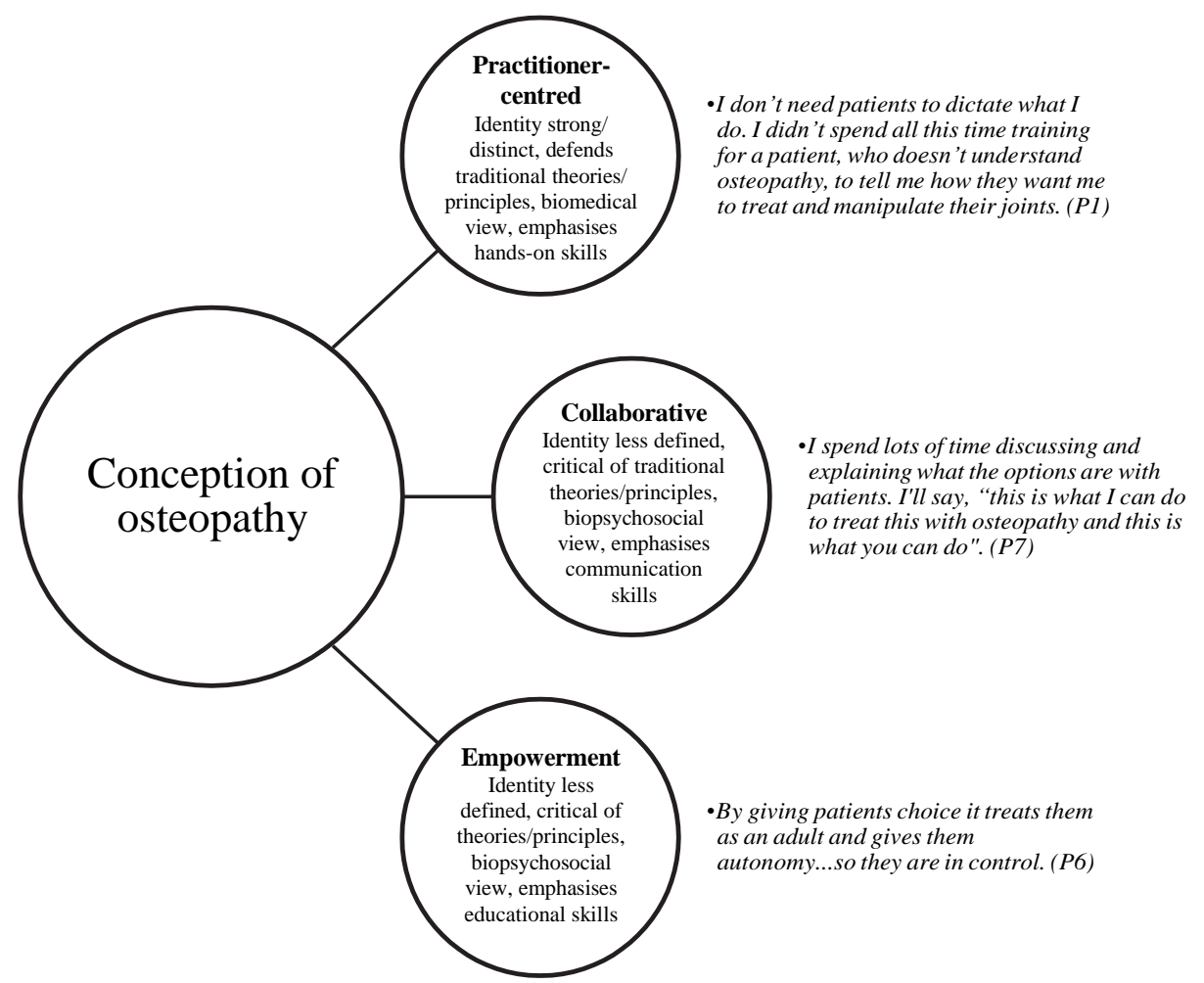

Fig. 1 Summary of participants' overall conception of osteopathy.

discussed below with illustrative comments provided.

\section{Practitioner-centred osteopathy}

For half of the participants $(P 1,2,5,8,11,12)$ a central feature of their conception of osteopathy was their application of specific osteopathic theories, hands-on skills and technical expertise. These participants emphasised their knowledge and their technical skills, suggesting a conception of osteopathy which was practitioner-centred:

I need to know what I'm treating. [and] I've got to know what the diagnosis is, so that I can get behind the reason for it and I can treat it. (P12)

Participants with a practitioner-centred conception of osteopathy emphasised applying their knowledge of osteopathic theories in combination with their hands-on skills to discover and treat patients' physical dysfunction. They possessed a view of health and disease which tended to focus on patients' biomedical impairment. These participants possessed a strong osteopathic identity which was characterised by their specific osteopathic hands-on skills, knowledge and theories which they considered distinctive from other health professions.
Collaborative osteopathy

A collaborative conception of osteopathy resulted in participants placing significant value on working with patients so that decisions could be made together. These participants $(P 3,4,8)$ emphasised collaboration and partnership with the patient, respecting them as an equal:

Having the patient onside and working with me facilitates a better relationship that I have with them. (P3)

Participants who conceived osteopathy as collaboration were ambivalent in regards to the importance of traditional osteopathic theories and principles in their clinical work; for them, using their interpersonal and communication skills to develop a therapeutic partnership with the person was central to their practise of osteopathy. These participants did not consider themselves as distinct osteopathic professionals; they saw themselves as individual healthcare therapists working alongside other healthcare professionals. They endeavoured to understand the patient's pain and physical dysfunction in the context of their lived experience and social situation, and communication was an important part of developing this understanding. In this regard they 
possessed a view of health and disease which considered the psychological and social aspects of the patient and their problem.

\section{Osteopathy as empowerment}

Participants in this group conceived osteopathy as a means by which they could facilitate patient empowerment. These participants $(\mathrm{P} 6,9,10)$ did not distinguish facilitating patient empowerment from their practise of osteopathy, and enabling patient learning was the basis of their treatment and management strategies. These participants considered their educational skills as central to their practice, which enabled them to support patient empowerment and self-management:

Osteopathic care is about helping to educate patients; it's about empowering patients to be able to look after themselves and make the most of their life. (P6)

Participants that conceived osteopathy as empowerment emphasised educating patients through sharing knowledge and valued the patient's own knowledge of their pain and disability. They embraced a psychosocial view of health and in doing so they considered the patient's problem in the context of their daily life and how it impacted their day-to-day functioning. These participants tended to be critical of long-held beliefs, traditional osteopathic principles, theories and customs and felt that hands-on skills alone were insufficient to help the patient self-manage their problem.

\section{Discussion}

This study is the first of its kind to explore the professional views, identities and conceptions of osteopathy of practitioners in the UK. The findings from this study suggest that osteopaths hold different views and perceptions of their professional identity, traditional osteopathic theories and principles, health and disease and practice skills, which together help shape their overall conception of osteopathy. The diversity of views and identities amongst the practitioners in this study is consistent with research investigating physiotherapists' professional identities and values. ${ }^{21,22,35}$ Previous research suggests that how these identities, views and conceptions are enacted during actual practice will influence osteopaths' clinical decision-making and ultimately the clinical approaches they take with their patients. ${ }^{18,19}$ Importantly, research suggests that the attitudes and beliefs of manual therapy practitioners (physiotherapists, chiropractors and osteopaths) in relation to common clinical conditions such as low back pain may influence their clinical decision-making and behaviour when caring for patients. ${ }^{36,37}$

In this study, individuals that conceived osteopathy as practitioner-centred emphasised their role as a distinct osteopathic professional that possessed the knowledge, skills and technical expertise to discover and treat the patient's problem. This finding is consistent with some osteopathic literature which proclaims that an important goal of the osteopath is the ability to find disturbances and abnormal segments within patients' bodies by skilfully employing hands-on examination and palpation procedures. ${ }^{38}$ This finding also echoes a mechanistic view of the founder of osteopathy, A.T. Still, who considered "man as an engine and the osteopath as a human engineer". $\quad$ Practitioner-patient interaction which overly emphasises patients' bodies (such as their movement and physical/structural characteristics) may limit practitioners' understanding to that of the objective reality of patients' anatomical, physiological and biomechanical dysfunctions. ${ }^{40}$ This view could be considered narrow and therefore fail to connect the physical impairment with patients' social world and lived experiences, which is necessary for a deeper understanding which is embodied and relational. ${ }^{41}$ Although some research suggests that practitioner-centred clinical practice is a characteristic of novice practitioners, ${ }^{42,43}$ in this current study there did not appear to be a qualitative association between practitioners' years of clinical experience and their conception of professional practice, and this finding is in agreement with others. ${ }^{44,45}$

Practitioners that conceived osteopathy as collaboration centred their practice on the therapeutic relationship and the sharing of knowledge and decision-making with the individual person. These practitioners emphasised talking and listening with patients above both providing handson treatment and facilitating patient empowerment. This finding echoes the concept of the 'therapeutic use of self' discussed in the psychotherapy, ${ }^{46}$ occupational therapy ${ }^{47}$ and nursing literature. ${ }^{48}$ It is maintained that the use of personal attributes as part of the therapeutic process offers alternative insights and perspectives, thereby facilitating professional judgement and developing a therapeutic relationship. ${ }^{46}$

Finally, practitioners that conceived osteopathy as empowerment focused their practice on educating patients, eliciting their personal preferences and their learning needs, and providing choice. Facilitating patient empowerment so that 
they can be involved in decision-making about their treatment and management involves situating the patient at the centre of their care. ${ }^{49}$ The literature argues that in practice, enabling patient empowerment requires placing the patient as professionals in their own right and experts of their own care, bodies, symptoms and situations. ${ }^{50}$ This echoes with the finding in this study, in that those practitioners that conceived osteopathy as empowerment sought to generate meaningful, patient-specific cues, pertaining to the impact that patients' pain and dysfunction has on their daily lives and activities. The literature suggests that interacting and communicating in this way facilitates a patient-centred approach to education and self-management of patients, particularly those with chronic conditions. ${ }^{50,51}$

The findings from this study suggest that some participants held practitioner-centred conceptions of osteopathy resulted in them focussing their clinical work on identifying the manifestations of physical ('somatic') dysfunctions within the patient's body regions. Such a focus on the physical 'osteopathic' impairment may overlook the patient as a person and their individual illness experience. Throughout the history of osteopathy, numerous theories and practice models have been espoused often from prominent individuals from specific corners of the osteopathic profession (for example $\left.e^{52 e 54}\right)$. Many of these theories tend to place the patient's body and the practitioner's knowledge and skills at the centre of practice, and offer ways in which the practitioner can correct and remove dysfunction and disability from the patient. Such practitioner-centred approaches may advocate inequality, promote patient passivity and facilitate practitioner paternalism. As the osteopathic profession matures, it should critically review such models and be confident in letting go of those theories and models which promote dualistic thinking, patient passivity and paternalistic care. This process of critical reflection may be made more challenging by resistance from practitioners who consider such practitionercentred approaches to be 'traditionally osteopathic' and form part of their 'unique selling point' within the competitive market of private manual therapy practice. If the profession fails to do so it risks being excluded from mainstream healthcare, policy and decision-making.

The physical and manual therapy professions are continuing to grow and are becoming increasingly competitive in the provision of musculoskeletal care. ${ }^{55,56}$ The increasing range of literature and CPD courses currently available, provide opportunities to cross-pollinate knowledge and skills between different healthcare professions. This may be particularly significant in relation to those professions where there are significant similarities, as is the case of the major manual therapy professions: osteopathy, physiotherapy and chiropractic. In response to such influences, it is possible that some members of the osteopathic profession, in an attempt to remain 'pure' and appear distinct, may uncritically adhere to osteopathic theories, models and traditions which overly emphasise the body, and its specific parts and segments (for example $\left.e^{53,57}\right)$. Many of these models are over fifty years old, and their positivist and biomedical slant reflects the period in which they were conceived. Uncritically accepting and rigidly applying dualistic theories, in light of the widespread acknowledgement of the social, psychological and behavioural factors of health, pain and disability ${ }^{58,59}$ may jeopardise the osteopathic professions' development and perhaps most importantly, fail to provide optimal patient care. Furthermore, a practitionercentred approach to practice appears to conflict with the Standards of Osteopathic Practice set out by the osteopathic regulator in the UK, which are explicit in stating that practitioners should "work in partnership with patients to help find the best treatment for them". ${ }^{60, p .8}$ Future CPD courses could be directed towards helping practitioners to foster critically reflective practice and promote patient collaboration and inter-professional cooperation in line with practice standards and essential for modern professional practice.

This study explored the views, identities and conceptions of osteopathy from the perspective of experienced practitioners, and how such conceptions are experienced and perceived by patients requires further research. Future studies could explore how these views, identities and conceptions of osteopathy develop though undergraduate education and evolve during professional life. ${ }^{20,35}$ Such knowledge would be useful to osteopathic educators and curriculum planners to help prepare students to develop a professional identity. The literature suggests that during professional education, practitioners begin to develop their own values, beliefs and philosophy of practice, which are considered to be some of the most influential forms of professional socialisation. ${ }^{20,61}$ It may be the case that undergraduate osteopathic education would have enabled groups of individual students to develop shared perspectives, common values and assumptions. ${ }^{62}$ Once qualified, practitioners may have also developed new perspectives and values based on the day-to-day social interaction in the workplace with other colleagues. ${ }^{22}$ Symbolic Interactionism Theory ${ }^{63}$ proposes that 
an individual's behaviour is influenced by the culture and context in which the social interaction is situated. This means that student osteopaths learning together may develop common 'takenfor-granted' assumptions of their professional role and identity, ${ }^{22}$ such as emphasising the importance of anatomy and a shared interest in biomechanics. Due to the long history of many of the OEls in the UK, (with some dating back almost 100 years), each institution is considered to have developed its own 'flavour' with their teaching and learning emphasising different aspects and interpretations of osteopathy. However, the findings from this study suggest no qualitative relationship between participants' conception of osteopathy and the OEI that they graduated from or which they worked.

Finally, further research could investigate the influences that the professional views, identities and conceptions have on clinical outcomes, and how they relate to clinical guidelines on common and professionally relevant conditions, such as chronic low back pain. ${ }^{37}$ The attitudes and beliefs held by practitioners regarding specific components of patient care, such as effective reassurance, self-management, return to work, and the provision of hands-on treatment in the short term, may all impact on patients' health outcomes with chronic musculoskeletal pain. ${ }^{37,64,65}$ These components could be investigated in relation to the different professional views, identities and conceptions developed from this study, with the potential to enhance the clinical effectiveness of osteopathic care.

There are several limitations to this study which should be highlighted. The limited number of practitioners which took part in this study means that transferability of the findings to the wider osteopathic and manual therapy professions needs to be established through further research. Furthermore, this research did not include osteopaths working within the public setting (NHS). Although these practitioners represent a relatively small proportion of the UK profession, ${ }^{66}$ it's possible that as a result of working within such a large, complex and multidisciplinary organisation as the NHS, such practitioners would have adopted quite different models of practice and held different professional views and warrants further research. ${ }^{67}$

\section{Conclusion}

Osteopaths in this study held a range of views in relation to their professional practice, and were characterised by the major categories of: professional identity, traditional osteopathic theories and principles, health and disease and practice skills. Individually, these views contributed to practitioners' overall conception of osteopathy, which was characterised as either practitionercentred, collaborative or empowerment. This diversity in professional identities and conceptions may help to explain the variation of individual osteopaths' clinical decision-making and clinical approaches, thereby contributing to an epistemology of osteopathy. Further research is required to explore how these views and conceptions impact on patient care as well as how they develop and evolve during undergraduate education and on-going professional development.

\section{Acknowledgements}

Thanks to the British College of Osteopathic Medicine, the British Naturopathic and Osteopathic Association and the Osteopathic Educational Foundation for helping to fund this doctoral research.

\section{References}

1. Cant SL, Sharma U. Professionalization of complementary medicine in the United Kingdom. Complement Ther Med 1996;4:157e62.

2. Howell JD. The paradox of osteopathy. N Engl J Med 1999; 341:1465e8.

3. General Osteopathic Council. What is osteopathy?, vol. 2012. London: General Osteopathic Council; 2010. Available from: http://www.osteopathy.org.uk/information/ about-osteopathy/.

4. Osteopathic Council of New Zealand. Capabilities for osteopathic practice volume 2012: the Osteopathic Council of New Zealand. Available from: http://www.osteopathiccouncil. org.nz/competency-standards.html; 2010.

5. Osteopathy Board of Australia. Osteopathy code of conduct. Osteopathy Board of Australia; 2011. http:// www.osteopathyboard.gov.au/Codes-Guidelines.aspx.

6. Richardson B, Higgs J, Dahlgren MA. Recognising practice epistemology in the health professions. In: Higgs J, Richardson B, Dahlgren MA, editors. Developing practice knowledge for health professionals. Edinburgh: Butterworth Heinemann; 2004. pp. 1e14.

7. Petty NJ, Scholes J, Ellis L. Master's level study: learning transitions towards clinical expertise in physiotherapy. Physiotherapy 2011;97:218e25.

8. Robertson VJ. Epistemology, private knowledge, and the real problems in physiotherapy. Physiotherapy 1996;82: 534e9.

9. Shaw JA, DeForge RT. Physiotherapy as bricolage: theorizing expert practice. Physiother Theory Pract 2012;28: $420 \mathrm{e} 7$.

10. Higgs J, Titchen A. Research and knowledge. Physiotherapy 1998;84:72e80. 
11. Munhall P. Nursing research. Jones \& Bartlett Learning; 2012.

12. Schultz PR, Meleis Al. Nursing epistemology: traditions, insights, questions. Image J Nurs Sch 1988;20:217e21.

13. Tyreman S. Valuing osteopathy: what are (our) professional values and how do we teach them? Int J Osteopath Med 2008;11:90e5.

14. Lucas NP, Moran RW. Is there a place for science in the definition of osteopathy? Int J Osteopath Med 2007;10: $85 e 7$.

15. Grundy M, Vogel S. Attitudes towards prescribing rights: a qualitative focus group study with UK osteopaths. Int J Osteopath Med 2005;8:12e21.

16. Parsons S, Harding G, Breen A, Foster N, Pincus T, Vogel S, et al. Will shared decision making between patients with chronic musculoskeletal pain and physiotherapists, osteopaths and chiropractors improve patient care? Fam Pract 2012;29:203e12.

17. Roskell C. An exploration of the professional identity embedded within UK cardiorespiratory physiotherapy curricula. Physiotherapy 2013;99:132e8.

18. Thomson OP, Petty NJ, Moore AP. Clinical decision-making and therapeutic approaches in osteopathy e a qualitative grounded theory study. Man Ther 2014. http://dx.doi.org/ 10.1016/j.math.2013.07.008.

19. Thomson OP, Petty NJ, Moore AP. A qualitative grounded theory study of the conceptions of practice in osteopathy: a continuum from technical rationality to professional artistry. Man Ther 2014;19:37e43.

20. Lindquist I, Engardt M, Richardson B. Learning to be a physiotherapist: a metasynthesis of qualitative studies. Physiother Res Int 2010;15:103e10.

21. Öhman A, Hägg K. Attitudes of novice physiotherapists to their professional role: a gender perspective. Physiother Theory Pract 1998;14:23e32.

22. Richardson B, Lindquist I, Engardt M, Aitman C. Professional socialization: students' expectations of being a physiotherapist. Med Teach 2002;24:622e7.

23. Thomson OP. Clinical decision making and therapeutic approaches of experienced osteopaths. University of Brighton; 2013 [Unpublished PhD thesis].

24. Charmaz K. Constructing grounded theory. London; Thousand Oaks, Calif.: Sage Publications; 2006.

25. Guba E, Lincoln Y. Competing paradigms in qualitative research. In: Denzin NK, Lincoln YS, editors. Handbook of qualitative research. Thousand Oaks, Calif.; London: Sage Publications; 1994. pp. 105e17.

26. Crotty M. The foundations of social research: meaning and perspective in the research process. SAGE Publications; 1998.

27. Cutcliffe JR. Reconsidering reflexivity: introducing the case for intellectual entrepreneurship. Qual Health Res 2003;13:136e48.

28. Morse JM. Strategies for sampling. In: Morse JM, editor. Qualitative nursing research: a contemporary dialogue. Rev. ed. Newbury Park, Calif.; London: Sage Publications; 1991. pp. 127e45.

29. Haw K, Hadfield M. Video in social science research: functions and forms. Routledge; 2011.

30. Thomson OP, Petty NJ, Scholes J. Grounding osteopathic research e introducing grounded theory. Int J Osteopath Med 2014. http://dx.doi.org/10.1016/j.ijosm.2013.07. 010.

31. Lincoln YS, Guba EG. Naturalistic inquiry. Beverly Hills, Calif.: Sage Publications; 1985.

32. Denzin N. Interpretive interactionism. Newbury Park: Sage Publications; 1989.
Special Committee on Osteopathic Principles and Osteopathic Technique by Kirksville College of Osteopathy and Surgery. The osteopathic concept. An interpretation. J Osteopathy 1953;60:7e10.

34. Seffinger M, King H, Ward R, Rogers F, Patterson M. Osteopathic philosophy. In: Chila AG, editor. Foundations of osteopathic medicine. 3rd ed. Wolters Kluwer Health/ Lippincott Williams \& Wilkins; 2010. pp. 3e46.

35. Lindquist I, Engardt M, Garnham L, Poland F, Richardson B. Physiotherapy students' professional identity on the edge of working life. Med Teach 2006;28:270e6.

36. Evans D, Breen A, Pincus T, Sim J, Underwood $M$, Vogel $S$, et al. The effectiveness of a posted information package on the beliefs and behavior of musculoskeletal practitioners: the UK Chiropractors, Osteopaths, and Musculoskeletal Physiotherapists Low Back Pain ManagemENT (COMPLeMENT) randomized trial. Spine 2010; 35:858.

37. Pincus T, Foster NE, Vogel $S$, Santos $R$, Breen A, Underwood M. Attitudes to back pain amongst musculoskeletal practitioners: a comparison of professional groups and practice settings using the ABS-mp. Man Ther 2007; 12:167e75.

38. Kappler RE. Palpatory skills and exercises for developing the sense of touch. In: Ward RC, editor. Foundations for osteopathic medicine. 2nd ed. Philadelphia: Lippincott Williams \& Wilkins; 2003. pp. 557e65.

39. Still AT. Autobiography of Andrew Taylor still. Kirksville; 1897.

40. Nicholls DA, Gibson BE. The body and physiotherapy. Physiother Theory Pract 2010;26:497e509.

41. Todres L. Being with that: the relevance of embodied understanding for practice. Qual Health Res 2008;18: $1566 \mathrm{e} 73$.

42. Smith M, Joy H, Ellis E. Effect of experience on clinical decision making by cardiorespiratory physiotherapists in acute care settings. Physiother Theory Pract 2010;26: 89 e 99.

43. Unsworth CA. The clinical reasoning of novice and expert occupational therapists. Scand J Occup Ther 2001;8: $163 e 73$.

44. Petty NJ, Scholes J, Ellis L. The impact of a musculoskeletal masters course: developing clinical expertise. Man Ther 2011;16:590e5.

45. Resnik L, Hart DL. Using clinical outcomes to identify expert physical therapists. Phys Ther 2003;83:990e1002.

46. Rowan J, Jacobs M. The therapist's use of self. Buckingham: Open University Press; 2002.

47. Taylor RR. The intentional relationship: occupational therapy and use of self. Philadelphia: F.A. Davis Co.; 2008.

48. Freshwater D. Therapeutic nursing: improving patient care through self-awareness and reflection. Sage Publications; 2002

49. Lawn S, McMillan J, Pulvirenti M. Chronic condition selfmanagement: expectations of responsibility. Patient Educ Couns 2011;84:e5e8.

50. Holmström I, Röing $M$. The relation between patientcenteredness and patient empowerment: a discussion on concepts. Patient Educ Couns 2010;79:167e72.

51. Anderson RM, Funnell MM. Patient empowerment: myths and misconceptions. Patient Educ Couns 2010;79:277e82.

52. Wernham J. The philosophy and mechanics of osteopathy. Maidstone Osteopathic Clinic; 1978.

53. Mitchell FL, Mitchell PKG. The muscle energy manual: volume one. MET Press; 1995.

54. Still AT. Osteopathy: research and practice. The author; 1910.

33. 
55. National Health Service. Any qualified provider ( $A Q P)$, vol. 2012. National Health Service; 2012. Available from: http: / /www.nhsemployers.org/ManagingTheTransition/ Pages/AnyQualifiedProvider(AQP).aspx.

56. NICE. Low back pain: early management of persistent nonspecific low back pain (Clinical guideline 88), vol. 2012. National Institute for Health and Clinical Excellence; 2009. Available from: http: //www.nice.org.uk/cg88.

57. Dove CL. The history of the osteopathic vertebral lesion. Br Osteopath J 1967;3.

58. Engel GL. The clinical application of the biopsychosocial model. Am J Psychiatry 1980;137:535e44.

59. Jones M, Edwards I, Gifford L. Conceptual models for implementing biopsychosocial theory in clinical practice. Man Ther 2002;7:2e9.

60. GOsC. General Osteopathic Council. Osteopathy in practicevol. 2013. London: General Osteopathic Council; 2012. Available from: http://www.osteopathy.org.uk/ practice/.

61. Richardson B. Professional development 1: professional socialisation and professionalisation. Physiotherapy 1999; 85:461e7.
Richardson B. Professional development 2. Professional knowledge and situated learning in the workplace. Physiotherapy 1999;85:467e74.

63. Blumer $\mathrm{H}$. Symbolic interactionism: perspective and method. Univ of California Press; 1986.

64. Carnes D, Homer KE, Miles CL, Pincus T, Underwood M, Rahman A, et al. Effective delivery styles and content for selfmanagement interventions for chronic musculoskeletal pain: a systematic literature review. Clin J Pain 2012;28:344e54.

65. Pincus T, Holt N, Vogel S, Underwood M, Savage R, Walsh DA, et al. Cognitive and affective reassurance and patient outcomes in primary care: a systematic review. Pain. http://dx.doi.org/10.1016/j.pain.2013.07.019.

66. General Osteopathic Council. Surveys \& statistics, vol. 2012. London: General Osteopathic Council; 2012. Available from: http://www.osteopathy.org.uk/resources/ surveys-statistics/.

67. Pincus T, Vogel S, Breen A, Foster N, Underwood M. Persistent back pain-why do physical therapy clinicians continue treatment? A mixed methods study of chiropractors, osteopaths and physiotherapists. Eur J Pain 2006;10:67e76.

62. 